\title{
Em busca de um tema esquecido: o lugar da educação nas recentes interpretações do Brasil
}

\section{Looking for a forgotten Subject Matter: the Place of Education in the Recent Interpretation of Brazil}

\author{
Marcos Cezar de Freitas ${ }^{1}$ \\ Universidade Federal de São Paulo (Brasil) \\ Luciano Mendes de Faria Filho ${ }^{2}$ \\ Universidade Federal de Minas Gerais (Brasil)
}

Recibido: 11-05-17

Aprobado: 25-05-17

\section{Resumo}

Este texto se propõe a analisar o lugar reservado à educação nas contemporâneas interpretações do Brasil. Para isso, escolhemos um conjunto de obras publicadas a partir do final do século XX, ocasião em que se avolumava as comemorações/discussões sobre os 500 anos do "descobrimento", até o ano de 2015, quando se instalou a crise que, como vimos, resultou no golpe civil parlamentar que destituiu a Presidenta eleita, Dilma Roussef, da Presidência da

\footnotetext{
${ }^{1}$ (marcoscezar@pesquisador.cnpq.br). Atua na área de Antropologia da Educação. Professor Livre Docente do Departamento de Educação da Universidade Federal de São Paulo. Coordenador da Plataforma de Saberes Inclusivos e Coordenador do Laboratório de Ensino e Vulnerabilidades Infantis (LEVI). Autor de: O professor e as vulnerabilidades infantis, com Renata Lopes Costa Prado, Cortez Editora, 2016; O aluno incluído na educação básica, Cortez Editora, 2014 e Alunos rústicos, arcaicos e primitivos. Cortez Editora, 2009.

2 (lucianomff@uol.com.br). Possui graduação em Pedagogia pela Universidade Federal de Minas Gerais (1988), mestrado em Educação pela Universidade Federal de Minas Gerais (1991) e doutorado em Educação pela Universidade de São Paulo (1996). É professor Titular da Faculdade de Educação da Universidade Federal de Minas Gerais, onde coordena o Projeto "Pensar a Educação, Pensar o Brasil" - 1822/2022, iniciativa desenvolvida em rede por mais de uma dezenas de instituições universitárias do Brasil. É co-autor, dentre outros trabalhos, de "Culture the people, build the nation: scientific and literary association and education in Minas Gerais (Brazil) at the beninning of the Brazilian empire. Paedagogica Historica" (Imprimé), v. 49, p. 82-89, 2013 e "The Invention of the Modern School in Brazil: Methods and Materials in Brazilian Schools in the 19th Century. In: Marcelo Caruso". (Org.): Classr oom Struggle Organizing Elementary School Teaching in the 19th Century. 1ed.Frankfurt: Peter Lang, 2015, v. 1, p. 127-156.
} 
República. $\mathrm{O}$ artigo defende que, se, ao longo do século XX, o acesso à educação foi panaceia para todos os males da nação, no século XXI, interpretar o Brasil tornou-se um exercício que permite abordar a permanência de quem chegou à escola, ampliando o foco do acesso para a inclusão, procurando entender, mais do que a transposição de limites, a aproximação, o fazer juntos que a quase universalização da escola básica possibilita. Mas também impõe entender as distâncias atualizadas e ampliadas entre a casa grande e a escola pública, no cultivo dos privilégios de classe e de raça de longeva tradição no Brasil.

Palavras-chave: Intérpretes do Brasil; Intelectuais; Escola Pública.

\begin{abstract}
This text is proposed to analyze the place reserved for education in the contemporary interpretations of Brazil. To do so, we chose a group of works published from the end of the twentieth century, time when commemorations / discussions about the 500 anniversary of the "Discovery" have been built up until the year 2015 when an Economic Crisis has been installed and resulted in the ousting of the Dilma Roussef from the Republic Presidency. The article defends that, if, throughout the twentieth century, access to education was "Panacea" for all the evils in the country, in the twenty-first century, interpreting Brazil became an exercise that allows us to approach the permanence of those who have got to school, increasing the focus of access for inclusion, aiming to understand more than just overpassing the limits, the approximation, the "doing together" that the almost universalization of the basic school provides. But it also imposes the understanding of the updated and extended distances between the Big house and the Public school on the fostering of class and race privileges, very tradition a land common in Brazil
\end{abstract}

Key-words: Interpreters of Brazil; Intelectuals; Public School

\title{
Introdução
}

Este texto resulta de exercícios intelectuais e políticos desenvolvidos há anos pelos seus autores. Juntos ou separados temos tentado responder a perguntas sobre os sentidos da educação nos projetos de Brasil elaborados nos últimos 200 anos pela intelectualidade e pelos movimentos sociais brasileiros.

O que vimos, ao longo de mais de 30 anos de pesquisa na área de história e antropologia da educação é que a educação escolar sempre foi, e continua sendo, um tema, um assunto, uma dimensão da vida social, fundamental nas discussões dos projetos para o Brasil. 
Isso é assim desde o momento em que fervilhavam os debates em torno da independência nacional. Conforme já tivemos ocasiões de demonstrar (Faria Filho, 2009), nos anos que se seguirem à independência e no momento de constituição do Estado Nacional e da Nação brasileira, a escola sempre foi tida e havida como uma das mais importantes instituições para a construção de um determinado "perfil de povo brasileiro".

No entanto, já naquele contexto despontava o problema a respeito do que seria, mesmo, o povo brasileiro. Em boa parte do século XIX, sob a égide das ideias civilização e civilidade, se concebia o "povo brasileiro" como uma massa amorfa que deveria adquirir uma forma, a de povo do Brasil, sob a direção de uma elite política e intelectual branca e sintonizada com a "civilização europeia".

Nossa constituição híbrida ou mestiça era vista, nesse enquadramento, no mais das vezes, como um de nossos grandes "obstáculos" para adentrarmos, como Nação, os caminhos da civilização. Na escola, de um lado e, em dado momento, nas práticas eugenistas de outro, eram depositadas as esperanças de fazermos do Brasil uma imensa Europa.

No último quartel do XIX, sobretudo, o investimento no elã da civilidade perde terreno para abrir espaço a uma concepção cada vez mais progressiva de história e de dinâmica do mundo social. O progresso, concebido ao mesmo tempo como uma teoria da história, como orientador da complexa trama do mundo social e como modo de entender o desenvolvimento de cada indivíduo, passar ser a pedra de toque dos investimentos de nossas elites.

O progresso, subordinado à presença da ordem (comando e ordenamento), chegaria a todos os rincões bafejados pela boa nova da presença estatal e, sobretudo, da instrução escolar, fosse ela pública ou privada. Foi sob a insígnia da ordem e do progresso, inscrita no panteão nacional, que os republicados, históricos ou de última hora, buscaram investir na disseminação da escola pública em todo o território nacional.

Formar e constituir um povo ordeiro e trabalhador passava a ser um das finalidades precípuas da escola, instituição cada vez mais defendida como de frequentação obrigatória para todas as crianças brasileiras. Ao mesmo tempo, boa parte da nossa intelectualidade defendia que, lá onde cessasse o alcance e poder da escola como agência de transformação da cultura pobre, grosseira e antiquada de nossa gente, restava a opção pela intervenção eugênica para a "purificação de nossa raça" e para a "elevação" de nosso caráter.

O caráter autoritário e racista de boa parte das propostas para o Brasil elaboradas sob a égide da civilidade e do progresso, também se ampliava na pretensão a formular um arcabouço conceitual e político que fosse abrangente o bastante para abordar o conjunto do mundo social, apontando tanto para dimensões individuais e pessoais quanto coletivas e/ou societárias da civilidade e do progresso. 
Não é por acaso que a educação escolar (ou, ao contrário, a sua ausência) fosse critério decisivo para creditar a presença maior ou menor civilidade ou progresso da pessoa e da sociedade como um todo. Se predominantemente as pessoas eram consideradas tomando por base o que não tinham, o que não eram, o que não conseguiam, a ausência de escolaridade despontava como "ausência essencial" indicadora de "impossibilidades atávicas".

Há uma inflexão expressiva, sobretudo no pós guerra, quando a noção de desenvolvimento passa a hegemonizar as discussões e elaborações sobre o mundo social e a educação. A presença do conceito de desenvolvimento no bojo das finalidades voltadas para a reordenação do país tem efeito amalgamante, que se desdobra em inúmeras correntes de pensamento até misturar-se às promessas da teoria do capital humano. Nessas perspectivas, o mundo social e, particularmente, a educação são tomados a partir de uma vertente nitidamente economicista, com a captura do pensamento social pelo pensamento econômico e pela redução da educação como estratégia de qualificação de recursos humanos para a competição numa ordem salarial que elaborava um capitalismo "próprio", herdeiro de seu próprio passado escravocrata.

No entanto, em que pese a presença dessas referências - civilização, progresso e desenvolvimento - no pensamento intelectual e nas políticas defendidas como necessárias ao país, essa presença sempre comportou tensões e dissensos dentre os intelectuais que se propuseram a interpretar e a transformar o Brasil.

Mesmo na segunda metade do século XX, momento de uma clara hegemonia das perspectivas desenvolvimentistas as mais diversas nas interpretações do Brasil, outras maneiras de interpretar o Brasil foram produzidas e mobilizadas, sobretudo no interior de movimentos sociais que se propunham a construir outro Brasil.

No entanto, no campo da educação, raramente tais interpretações ganharam os corações e mentes de nossa intelectualidade e, mesmo, dos políticos brasileiros, pois não lograram fundamentar políticas e, muito menos, práticas educacionais, malgrado o esforço de muitos daqueles e daquelas que militaram no campo educacional.

O tema educação escolar, mencionado ininterruptamente como necessário e fundamental tornou-se, no século XX, expressão de um paradoxo. Mencionado por todos, não deixou de ser "coisa de educadores".

A questão da educação do povo nos remete, pois, às múltiplas interpretações do Brasil e o lugar nelas reservado à educação. Se, como já se disse, há um esforço coletivo sendo feito para compreender esse fenômeno em nossa história, nesse momento nosso olhar se volta, mais especificamente, para o tempo presente. É nele e a partir deles que indagamos: qual o lugar reservado à educação nas contemporâneas interpretações do Brasil? 
Para responder a essa questão, escolhemos um conjunto de obras publicadas a partir do final do século XX, ocasião em que se avolumava as comemorações/ discussões sobre os 500 anos do "descobrimento", até o ano de 2015, quando se instalou a crise que, como vimos, resultou no golpe civil parlamentar que destituiu a Presidenta eleita, Dilma Roussef, da Presidência da República.

Nesse texto, especificamente, compartilhamos a leitura que fizemos de algumas interpretações recentemente publicadas e organizamos um vetor de busca argumentativa. Ou seja, se por mais de um século o acesso à educação foi panaceia para todos os males da nação, no século XXI, com interpretar o Brasil tornou-se um exercício que permite abordar a permanência de quem chegou, ampliando o foco do acesso para a inclusão, procurando entender mais do que a transposição de limites, mas também a aproximação, o fazer juntos que a quase universalização da escola básica possibilita aos que se esforçam por interpretar "o que somos, com base no que fizemos".

\section{Brasil no século XXI: um país em busca de intérpretes?}

Quantos são os modos de se interpretar o Brasil e quais são os sujeitos que se colocam essa tarefa? Essa é uma pergunta de fácil elaboração e de difícil resposta, dado o caráter polissêmico da própria noção de interpretação.

Recentemente a Fundação Perseu Abramo publicou um denso estudo relacionado às percepções e valores políticos presentes nas periferias de São Paulo (FPA, 2017). A pesquisa abordou, especificamente, um segmento eleitoral composto por pessoas que se beneficiaram de programas sociais e que deixaram de votar no espectro político partidário que se apresenta com plataformas do centro para a esquerda.

Percebeu-se que esses sujeitos assumiram, desde 2014, uma perspectiva eleitoral claramente identificada com o léxico político que contém as "palavras chave" (Williams, 2010) do movimento eleitoral que se desloca do centro para a direita.

Aos pesquisadores responsáveis por essa aproximação em relação ao tecido ideológico que se guarda sob o teto dos cinco salários mínimos como renda máxima foi possível constatar uma "adesão" às palavras chave de um processo que amalgama um severo conservadorismo de costumes, com perspectivas de um neoliberalismo radicalizado.

No conservadorismo de costumes são pronunciadas as reverências à superioridade da meritocracia e na assimilação radicalizada do neoliberalismo são pronunciadas as abjurações aos princípios dos direitos sociais que até então lhes serviam àqueles que responderam às questões da pesquisa.

Tais pessoas, segundo o conteúdo divulgado, participam da evocação do empreendedorismo como quem clama por um mundo não contaminado pela 
corrupção política e se posicionam na mesma trincheira da qual são lançados os ataques ao Estado, aos impostos e aos "privilégios sindicais".

A pesquisa repercutiu e foi imediatamente apropriada pela grande imprensa que encontrou nas falas dos moradores das pobres periferias de São Paulo o mote para escrever que os que falam "em nome do povo" não conhecem a realidade "de perto". Serviu, segundo essa visão, para denunciar um "déficit de intérpretes e interpretações" neste século que já está quase concluindo sua segunda década, mas que ainda reverbera problemas do século XIX.

Essa imprensa constantemente flagrada em seu indisfarçável elitismo se vale do conteúdo da pesquisa para expor suas teses a respeito dos chamados problemas nacionais. Por isso mesmo, é no espaço destinado aos editoriais que se pronuncia. No caso específico, aproveitam as bases da pesquisa para expor linhas e, principalmente, entrelinhas. Proclamam o fim dos efeitos sedutores daqueles que advogam a presença do Estado na articulação de políticas sociais e que ostentam promessas republicanas como as que defendem a educação pública, laica, universal e gratuita ao lado do sistema público, universal e gratuito de acesso à saúde.

Saúdam, com indisfarçável desfaçatez, a "descoberta" de uma "ética empreendedora" agora localizada nas populações de baixa renda. Isso reavivou diagnósticos que circulavam na década de 1950, quando os que defendiam a "superioridade" da escola privada sobre a escola pública apresentavam o argumento que os pobres querem "progredir" e que as famílias querem "escolher" e que, em decorrência, querem "merecer o que têm" (Buffa, 1979, Freitas e Biccas, 2009, Weinstein, 2000).

Pode parecer apenas uma cena de um enredo no qual pessoas pobres e muito pobres manifestam encantamento com valores que fazem parte da lógica daqueles que os subjugam. No entanto, a altíssima complexidade que permeia esse deslocamento eleitoral diz respeito não somente às exacerbações conservadoras no campo dos costumes, mas à adesão a valores econômicos, políticos e jurídicos que, no limite, retomam aquilo que Oliveira Vianna, um ícone de um autoritarismo com punhos de renda afirmava na década de 1940, segundo quem "exotismos" como luta de classes, democracia representativa são estranhos à "personalidade do país" (Vianna 1949).

A pesquisa em tela deve ensinar algo aos que formulam e defendem direitos sociais e políticas públicas. Mas deve também chamar atenção para o universo ideológico da apropriação dos seus resultados. Esse é um campo de lutas que sugere a permanência dos temas das interpretações e dos intérpretes do Brasil como dado a ser constantemente revisitado. Os que se apropriaram dos resultados da pesquisa para promover o esvaziamento de direitos sociais ocupam um espaço descrito pelos mesmos como de "oportunidade para renovar interpretações do Brasil”. 
No âmbito dos enfrentamentos ideológicos que estão presentes no cenário em que esses resultados de pesquisa se apresentam, observamos muitos protagonistas terçando armas para enfrentar a batalha que, ao termo, segundo seus propósitos, haverá de limitar (ou quem sabe destruir completamente) a esfera pública brasileira, reduzindo-a ao tamanho do "oportuno", ou seja, às dimensões que não possam atrapalhar a família e o empreendedorismo.

Chama atenção, porém, a forma através da qual se reapresenta a textura do "moderno". A apropriação que a grande imprensa fez e faz dos resultados da pesquisa da Fundação Perseu Abramo interpreta o país sintetizando-o numa errância de ordem configuradora e de pronúncia profética: não se modernizará enquanto não disciplinar, conter e limitar sua esfera pública.

O moderno, mais uma vez ressurge como negação de quaisquer representações de coletividades e se agita dentro do estojo com o qual nossa "cegueira política" tem guardado o mérito como motor da história.

E, mais uma vez, os trabalhadores, as parcelas consideradas rústicas, arcaicas e primitivas entram em cena pela via da negatividade. Ou seja, retomando a rica análise proposta por Paoli e Sader (1986), a descrição das personagens que estariam agora descobrindo uma nova ética estariam a caminho do mesmo lugar para onde se dirigirá o país quando se livrar dos seus atrasos.

À medida que esses atrasos são identificados com a hipertrofia da esfera pública, que agigantada inibiria o moderno de irromper nas fendas do cimento bruto do arcaísmo que se alimenta de programas sociais, essa população "que não é" faz par com o país "que não tem".

Por isso, o suposto deslocamento de perspectiva eleitoral que agora é festejado por tais setores produtores de opinião, não diz respeito à mobilidade social, à aproximação, ao acesso a bens de direito.

A mobilidade social, vista com desconfiança porque feita à custa de arcaísmos como, por exemplo, transferência de renda, diz respeito a pessoas "incompletas" que no acesso às instituições estariam impregnando-as de inconsistência e precariedade, porque estariam chegando "com a falta de": estariam chegando sem bases argumentativas, sem bases analíticas e sem condições prévias para honrar acessos obtidos via expansão de direitos.

É importante notar que na segunda década do século XXI produzimos diagnósticos semelhantes àqueles que na segunda década do século $\mathrm{XX}$ indicavam que o país não tinha um povo a altura dos desafios republicanos que se apresentavam. Não é obra do acaso que naquele contexto fosse possível afirmar que a república que tínhamos, não era a república sonhada. Produzia-se, então, um vaticínio que permitia antever outro futuro, um futuro desgrudado das heranças do passado e finalmente moderno porque levado a efeito através da ampliação do acesso à escola. 
Nas duas décadas seguintes portentosas interpretações do Brasil foram publicadas e o ponto de desvendamento que proporcionaram dizia respeito a entender o profundo de um país singular, urdido nas tramas de um lugar com impressionante capacidade para criar e recriar hierarquias sociais.

Os clamores por interpretações do Brasil pronunciados na década de 1920 encontraram ecos nas intenções analíticas que resultaram nos títulos que a partir da década de 1930 passaram a explicar o "comportamento social" à luz das formas como aqui se degradavam as relações entre esferas pública e privada, entre ação individual e coletiva, entre os domínios da casa e do Estado.

Os intérpretes do Brasil a partir da década de 1930, como Gilberto Freyre, Sérgio Buarque de Holanda e Caio Prado Júnior, foram cuidadosos ao lembrarem que o país já contava com interpretações desde o século XIX e, em alguns aspectos específicos, desde a experiência colonizadora. Identificar a presença de determinado tema no coração argumentativo dos intérpretes do Brasil é, portanto, um movimento exegético possível e necessário.

Quando a grande imprensa destaca que a "personalidade do país mudou" e que faltam intérpretes para conhecer essa realidade de perto, se produz uma análise superficial. É superficial porque o pensamento social brasileiro não fez outra coisa que não tentar decifrar enigmas a respeito das atitudes, posicionamentos e indiferenças diante dos chamados grandes problemas nacionais.

Essa é quase a síntese do trabalho intelectual que há décadas, com variações ideológicas, metodológicas e epistemológicas, interpretou o que somos e, principalmente o que não somos. É isso o que possibilita a pesquisadores buscar por especificidades, como por exemplo, a construção da família em tal obra, a identificação do Estado em tal autor e assim por diante.

Que o país sempre resulte embasbacante em qualquer interpretação não nos surpreende, mas nesse mar de leitores e leituras do Brasil alguns temas têm maior incidência do que outros. Dentre esses, o tema educação nos interessa de perto.

$\mathrm{Na}$ ampla e vistosa estante em que estão os intérpretes do Brasil, do século XIX para o século XX, o tema educação pouco aparece justamente porque em muitas interpretações a educação era indicada como dado ausente a explicar crônicos problemas e a indicar estratégias curativas para os males da nação, mediante a irradiação de saberes escolarizados.

A educação como tema das interpretações não despontava porque para a maioria daqueles intérpretes se desvendava um passado de alguma forma plasmado na experiência colonial e, quando muito, abordar a educação significava refletir porque dela tínhamos tão pouco. Na maioria das sínteses, teses e antíteses a educação despontaria, quando aparecesse como antídoto aos males herdados de um passado infausto e vergonhoso. 
Embora seja tema essencial em Manoel Bonfim(1868-1932), por exemplo, lembrado sempre para decifrar o enigma chamado Brasil, em sua interpretação "os males de origem" são mais importantes analiticamente que a educação em si, enquanto vetor de interpretação.

O século XXI já produziu novas leituras e interpretações de Brasil. Nada que se compare ao processo que gerou as sínteses das décadas de 1930 e 1940, mas num outro contexto já estamos novamente interpretando o país. Mas e os novos intérpretes que têm o próprio século XX palco de grande expansão nos números escolares, como voltam ao passado e, em voltando, o que percebem, se é que percebem, da educação?

No que diz respeito ao tema educação, é fundamental lembrar que entre um contexto e outro, no transcorrer do século, o país produziu expressiva expansão nos seus números escolares. Há que se perguntar pelo lugar reservado para a educação escolar nas interpretações "de agora" que puderam contar com a expansão dos números educacionais e pensar sobre a ausência, mas também sobre a presença da escola pública em nosso tecido social.

\section{A educação nos novos intérpretes do Brasil}

Em nossas investigações, estamos mergulhados num processo de permanente mapeamento das interpretações sobre o Brasil. No entanto, convém avisar que esse texto não é um estado da arte, tampouco um levantamento sobre quais e quantas são as atuais interpretações do Brasil no século XXI.

Estamos escrevendo à medida que se torna possível recolher em certas obras a presença ou ausência do tema educação. Especificamente aqui estamos analisando brevemente os livros publicados de Botelho e Schwarz (2009) Um enigma chamado Brasil, de Botelho e Schwartz (2011) Agenda brasileira, de Schwarz e Starling (2015) Brasil, uma biografia e de Mota e Lopez (2015) História do Brasil: uma interpretação.

Para perguntar do tema educação nas novas interpretações do século XXI é importante afirmar que as novas interpretações não puderam (nem quiseram) ignorar a fortuna historiográfica precedente.

Os intérpretes com suas interpretações de Brasil poucas vezes explicitaram nos títulos de seus trabalhos a intenção de interpretar. O reconhecimento de que uma interpretação fora levada a efeito na maioria das vezes resultou da circulação e da apropriação dos pressupostos desenvolvimentos em cada análise. Ou seja, foram os leitores os responsáveis pelo reconhecimento de que determinada obra tinha a grandeza e a profundidade de uma interpretação de país, evidentemente com adesões e rejeições. Foi o que aconteceu, por exemplo, quando a categoria "formação" 
foi percebida como estratégica nas interpretações que despontaram entre as décadas de 1940 e 1960.

Obras como "Formação histórica do Brasil", de Nelson Werneck Sodré (1962), mas principalmente "Formação do Brasil Contemporâneo de Caio Prado Júnior" (1953), "Formação econômica do Brasil” de Celso Furtado (1959) e, pouco mais adiante, "Formação da literatura Brasileira", de Antonio Candido (1959) mostraram, cada qual com seus pressupostos e opções temáticas e teóricas, que com a categoria formação era possível indicar que com uma representação de processo, que retomado ao inverso sugeria certa organização genealógica, era possível apresentar uma interpretação de país.

Em relação ao tema "pensamento", exercícios de adesão e rejeição aparecem de tempos em tempos, muito especialmente quando o "específico do homem brasileiro" por algum motivo vem à tona, tal como na pesquisa mencionada ao início, por exemplo.

Um exemplo recente foi a objeção que Jessé de Souza (2015) apresentou à interpretação de Sérgio Buarque de Holanda.As fagulhas críticas do sociólogo se voltaram contra aquele que, segundo ele, é uma das "vacas sagradas" de nossa historiografia. E isso é feito, sobretudo, num capítulo de sua obra recente que se intitula, sintomaticamente, "Cordial e colonizado até o osso - O liberalismo amesquinhado chega ao Brasil Moderno” (p.39).

Para Jessé de Souza, Sérgio Buarque é uma espécie de "filho bastardo" de Gilberto Freyre, que herda do pai tudo que é essencial, sem ter, no entanto, o brilhantismo do mesmo. Sérgio Buarque teria herdado "os pressupostos de seu pensamento e de sua visão de mundo" (p.39), calcados no que chama de "culturalismo brasileiro", responsável pela criação do "mito nacional" da singularidade cultural brasileira.

Disso teria resultado a ideia do "homem cordial brasileiro" e, em sua forma institucionalizada, o chamado "patrimonialismo" "em que o Estado e seus agentes passam a agir como o homem cordial age na vida cotidiana: dando tudo aos amigos e reservando aos inimigos a letra dura da lei"(49).

O autor elabora dura crítica para expor a inconsistência de um anti estatismo que, no Brasil, se alimentaria de muitas e contraditórias fontes, inclusive do modo de se interpretar a chamada singularidade brasileira.

Na edição dominical dos jornais Folha de S. Paulo e o Globo, do dia 26 de março de 2017, o jornalista Elio Gáspari, comentado a recém publicada biografia de Tancredo Neves (Fraga, 2017) destacou a seguinte informação:

O menino Tancredo teve um pajem, o negro Custódio, neto da cozinheira da família Neves, que nela continuou depois da Abolição. Custódio ficou com os Neves até morrer, aos 90 anos, anexando o sobrenome dos velhos senhores. Sabendo-se disso, conhece-se a alma patriarcal de Tancredo. 
A anexação do sobrenome dos velhos senhores é parte de um enigma? Um enigma chamado Brasil? Foi com esse título que Botelho e Schwarcz (2009) revisitaram o tema dos intérpretes do país e produziram densa coletânea mobilizando expressivos estudiosos do pensamento social brasileiro.

Esses indicaram quais intérpretes deveriam ser chamados para que se repusesse o país como enigma e descreveram os fundamentos de cada interpretação, nas obras de referência dos intelectuais analisados.

Não se faz necessário apresentar qualquer objeção às escolhas porque trabalhos dessa natureza não têm mesmo que abranger a tudo e a todos. Embora seja possível estranhar a ausência de Anísio Teixeira, Fernando de Azevedo, Celso Furtado e Álvaro Vieira Pinto, é importante reconhecer que estão presentes as referências a autores e obras que inegavelmente interpretaram o Brasil: Alberto Guerreiro Ramos, André Rebouças, Antonio Candido, Caio Prado Jr, Darcy Ribeiro, Euclides da Cunha, Fernando Henrique Cardoso, Florestan Fernandes, Francisco José de Oliveira Vianna, Gilberto Freyre, Gilda de Mello e Souza, Joaquim Nabuco, José Inácio Silveira da Mota, Luis Aguiar Costa Pinto, Luis da Câmara Cascudo, Manoel Bomfim, Maria Isaura Pereira de Queiroz, Mario de Andrade, Marquês do Paraná, Octávio Ianni, Oracy Nogueira, Paulo Prado, Raimundo Nina Rodrigues, Raymundo Faoro, Richard Morse, Roberto Schwarz, Roger Bastide, Sérgio Buarque de Holanda, Silvio Romero, Teófilo Otoni e Visconde do Uruguay.

De certa forma, todos os autores têm em seus escritos um "ponto de desvendamento", de cuja compreensão depende o entendimento proposto pelo intérprete a respeito do que somos, do que não somos, do que jamais seremos $\mathrm{e}$, fundamentalmente, uma proposta para que o leitor compreenda a origem de nossos dilemas, incompletudes e insuficiências. Identificada a origem desses dilemas, incompletudes e insuficiências materializa-se a percepção de arcaísmos, anacronismos e esmagamentos sociais, tudo e todos amalgamados com violência e conciliação perene.

No entanto, dentre os 29 intérpretes escolhidos para compor o livro, nenhum dedicado a discutir a escola pública. Nem mesmo Fernando Azevedo, com seu monumental livro, A cultura Brasileira, e com seu lastro institucional e acadêmico, logrou presença entre os escolhidos. Disso resultando, dentre outros, que a questão da educação escolar, sua presença ou ausência, não comparece como uma dimensão fundamental de busca para e nas interpretações do Brasil.

Esses mesmos intelectuais e pesquisadores organizaram, na sequência da primeira, uma obra, Agenda Brasileira (2011), em que, aí sim, e sintomaticamente, aparece um capítulo sobre a educação. Reconhecem, portanto, que a educação é um componente fundamental da tessitura do país na atualidade e, sobretudo, na construção do país do futuro. 
A mesma historiadora Lilia Schwarz se associou à também historiadora Heloisa Starling para produzir Brasil, uma biografia (2015), obra também recente e de grande sucesso editorial (várias impressões com milhares de exemplares vendidos num único ano). O propósito, segundo as autoras, é utilizar gênero biográfico como uma fórmula para "conhecer os muitos eventos que afetaram nossas vidas, e de tal modo, que continuam presentes na agenda atual”:

\begin{abstract}
A história do Brasil, por suposto, não cabe num único livro. Até porque não há nação cuja história possa ser contada de forma linear, progressiva, ou mesmo de uma só maneira. Assim, aqui não se pretende contar uma história do Brasil, mas fazer do Brasil uma história. Ao contar a história, tanto o historiador quanto o leitor aprendem a 'treinar a imaginação para sair em visita', como diria Hannah Arendt. E é por levar a sério essa noção de 'visita' que este livro deixará de lado a meta de construir uma 'história geral dos brasileiros' para se concentrar na ideia de que a biografia talvez seja outro bom caminho para tentar compreender o Brasil em perspectiva histórica: conhecer os muitos eventos que afetaram nossas vidas, e de tal modo, que continuam presentes na agenda atual (2015.p19).
\end{abstract}

No entanto, apesar da riqueza de informações, cuidado com o texto e a beleza das imagens que compõem o volume, se considerada apenas a biografia apresentada no livro, o Brasil é um país que não foi à escola! Pelo menos até hoje! Da nossa "difícil e tortuosa construção a cidadania”(2015.p.14), resulta um país marcado pela violência, pelas desigualdades e pelo analfabetismo, dentre outras características, em que

"Apesar de não existirem formas de discriminação no corpo da lei, os pobres e, sobretudo, as populações negras são ainda os mais culpabilizados pela justiça, os que morrem mais cedo, têm menos acesso à educação superior pública ou a cargos mais qualificados no mercado de trabalho.’(2015.p.15).

Vemos que a educação aparece fortemente associada à agenda do presente, àqueles problemas que precisamos superar e enfrentar. No entanto, salvo raríssimas exceções, e uma delas é a referência a Paulo Freire, a escola pública não aparece como tema relevante nessa história que se quer contar e nessa interpretação que se quer estabelecer.

Para se ter uma ideia, no índice remissivo do livro não há lugar para as palavras educação ou instrução, enquanto há para samba (13 vezes) ou para Marinha Brasileira (26 vezes), por exemplo. Mesmo a palavra escola, quanto aparece no índice remissivo, é para se referir ao ensino técnico ou ao ensino superior. Assim, não parece ser por acaso, que dentre as centenas de referências bibliográficas distribuídas por 28 páginas não há nenhuma sobre educação.

Se nosso passado educacional é esquecido, teria a recente e triunfante associação entre educação e meritocracia suas raízes já explicitadas nessa fortuna interpretativa? 
Se a educação escolar foi abordada superficialmente nas interpretações do Brasil, tendo sido obviamente objeto dos historiadores da educação (cuja historiografia nunca foi guindada ao panteão dos intérpretes, vide a já mencionada ausência de Fernando de Azevedo na obra comentada), ela permanece como patrimônio interpretativo para novas interpretações. Ela pode ou poderia ser uma diferença qualitativa dos novos intérpretes.

O tema educação foi o mote de interpretações do Brasil feitas por intelectuais da educação que produziram, simultaneamente, leituras sobre o país enquanto predicavam a educação pública que acreditavam necessária e imprescindível, como os já citados Fernando de Azevedo (1940) e Anísio Teixeira (1962).

Mas deixar a educação escolar de fora das recentes interpretações significa também abster-se de analisar um dos aspectos mais tensos da sociedade brasileira. Pouco ou nada abordada, a expansão das oportunidades educacionais é analisada, quando é, no registro do acesso, ou seja, da oferta de vagas.

Porém, o que é do processo em que o próprio tecido social passa a ser também entretecido pelos fios que conectam a convivência escolar aos modos de aproximação entre diferenças e diferentes? Acessibilidade é uma dimensão da conquista de direitos. Inclusão é o processo em que as partes passam a interagir.

\section{Qual escola, qual acessibilidade e qual inclusão?}

Uma disponibilidade a apresentar especificamente uma interpretação da história do Brasil foi assumida por Carlos Guilherme Mota e Adriana Lopez em 2008, quando publicaram a primeira edição de "História do Brasil: uma interpretação”, obra atualizada em várias edições até 2015. Os autores produziram cuidadosa leitura panorâmica a respeito do país, abrangendo um universo de análise do século do XVI ao XXI.

Ecoando a erudita conformação da historiografia francesa, o Estado nacional e as sucessivas configurações governamentais (e seus efeitos) permeiam a interpretação e dão "sentido" ao fio que vai sendo desnovelado em mais de mil páginas. O século XX está exposto e a trama se estende quase que aos dias atuais.

Tal abrangência suscita a expectativa de encontrar nessa interpretação a escola pública como personagem essencial, sem a qual, inúmeros cenários restam indecifráveis. Em relação ao século XX, a educação é tema recorrente no desenvolvimento factual e analítico dessa obra de fôlego, a começar pelo registro que o tema encontra nos lamentos de muitos intelectuais que compuseram os pontos e contrapontos da ordem republicana. 
O lamento de Paulo Prado a respeito do "analfabetismo das classes inferiores" é anotado como estratégia para trazer ao texto o tema da imitação e da inautenticidade da sociedade brasileira (p. 525).

E são registradas algumas iniciativas governamentais que operam, principalmente a partir de 1910, a produção de ensino para ofícios. Mas rapidamente se percebe que as menções à educação ganham algum detalhamento quando se faz possível explicitar os efeitos da escassez de ensino superior ou para predicar a importância da universidade.

A ampliação da rede escolar vai sendo registrada numa narrativa que evoca a escola pública, mas se adianta em direção à crítica aos bacharelismos.

O Ministério da Educação e Saúde torna-se um protagonista na percepção de que "um direitista" o fizera, Francisco Campos, e que a irrupção da burocracia estatal da educação ao tempo em que solucionou antigas pendências e propulsionou alguma expansão, não foi suficiente para impedir que a lucidez de Anísio Teixeira proclamasse que no Brasil “(...) o homem culto, à medida que se cultiva, mais desenraiza, mais se afasta do meio comum e mais se afirma pelo exclusivismo e particularidade da sua luta pessoal pelo saber ... (Mota e Lopes, 2008.p.645).

E é assim que com erudita recuperação das ações e limitações das ações ministeriais o texto no seu todo vai se abrindo para revelar que no seio de muitos impasses o tema da educação pública se fez presente como bandeira.

Por isso, desponta o Manifesto dos Pioneiros de 1932 e, com a Era Vargas ao fundo, vai se compondo uma análise sobre a formação intelectual de nossas elites, (e entra em cena a Universidade de São Paulo), e no ensejo de abordar elitismos os autores percebem o Ministério Gustavo Capanema como articulador de uma visão excludente de ensino secundário.

A crítica sempre lúcida de Darcy Ribeiro ao processo de estruturação do ensino profissionalizante do país é lembrada e o legado da Era Vargas é sintetizando em tom que admite convergências nem sempre sustentáveis:

\footnotetext{
(...) O legado maior desse período (...) foi a reforma do ensino conduzida sob a coordenação do Ministro Gustavo Capanema, incorporando ideias de educadores como Anísio Teixeira, Fernando de Azevedo, Almeida Júnior e outros. Sua importância deveu-se ao fato de serem homens de ideias e de pesquisa, professores, formadores de 'escolas de pensamento' e, também, de atuarem em políticas públicas... Momento de importante expansão da Escola Pública, democratizante e laica e de uniformização do ensino em escala nacional ...(Mota e Lopes, 2008 p. 710).
}

Notamos que Escola Pública foi grafada com maiúsculas. Considerávamos que uma vez anunciada assim, na sequência, esse ente digno de tal reconhecimento despontaria como elemento necessário na elucidação de inúmeros fios entretecidos 
no tecido social que se fez cada vez mais complexo no transcorrer do século.

Mas à medida que a expansão se intensifica, e até o final do século XX a oferta de vagas aumentou expressivamente se comparada com a situação que finalizou o século XIX, a personagem de destaque - a Escola Pública- volta a ser um tema dentro das discussões sobre o Estado.

São brilhantes as análises sobre a Universidade de Brasília idealizada por Darcy Ribeiro. É cuidadosa a recuperação de dados sobre a Lei de Diretrizes e Bases de 1996 que é utilizada para demonstrar o horror causado pelo golpe civil militar de 1964 e suas muitas e nocivas ações no âmbito da educação.

Mas os principais efeitos dos desatinos cometidos pelos governos militares são vislumbrados no âmbito do acesso ao ensino superior. A trama segue como se a escola pública já tivesse sido mencionada nas cenas em que os intelectuais se manifestaram ou nas leis que conferiram efeitos legais aos seus propósitos.

Os tempos sob o governo Fernando Henrique Cardoso oferecem oportunidade para comentar a expansão de instituições privadas no ensino superior e a consolidação de avaliações de larga escala é comentada e contextualizada. Mas essa interpretação da história do Brasil termina com a escola pública mencionada e não analisada.

\section{Considerações finais: a escola ignorada nas interpretações é a escola da maioria, a escola dos "filhos dos outros"!}

Interpretar o Brasil, em perspectiva histórica, é um exercício que demarca, de certa forma, um território analítico ainda aberto às visitações mais contínuas. Esse território "menos visitado" em termos históricos é o Brasil do século XX, especialmente após a década de 1940.

Convém lembrar que essas incursões com horizontes cronológicos tão "próximos" são compreensivelmente evitadas por historiadores justamente porque esses têm no desvelamento do "tempo longo" um recurso fundamental para construir ou aderir à determinada acepção de processo. A percepção de rupturas ou de permanências, por exemplo, é bastante dependente da estratégia com a qual o autor analisa forma e conteúdo. Ou seja, o que dá forma desloca e plasma conteúdos.

A escola tornou-se a forma de expandir conteúdos educacionais. Ela não é naturalmente o locus de obter educação. Ela é sempre construção. Cabe sempre perguntar como ela foi feita e não somente como foi dada ao acesso.

Essa é uma questão que adquire especial relevo quando o historiador do século XXI decide interpretar o Brasil: desse "lugar", o de novo intérprete, o século XX não pode ser ignorado na complexidade de uma trama que se tece, e a essa não não é possível entender sem a presença da escola pública. 
O século XX foi aberto com expressivo número de atores políticos se apresentando para resgatar a dívida educacional do século XIX. A história das reformas educacionais da década de 1920, o impacto do Ministério de Educação e Saúde, na década de 1930, o pós segunda guerra, as desastrosas consequências do golpe civil militar de 1964, a recuperação cidadã ensejada na Constituição de 1988, parecem delinear um único roteiro que, uma vez perfilado, teria o condão de assegurar o espaço "ao educacional" dentro da interpretação.

Nas entrelinhas, essa passada ligeira do texto pelo universo das escolas públicas parece indicar que o detalhe, o pormenor, o singular e específico seria objeto de especialistas. Por outro lado, é interessante pensar, porém, que a maior parte das interpretações sobre o Brasil não se distanciou dos temas desigualdade e diversidade na sociedade brasileira. Temas que adquiriram densidade variável conforme a perspectiva de registro.

Mas foi justamente com o advento da escola pública multitudinária que aspectos muito sensíveis de nossas desigualdades e diversidades se mostraram, se entreteceram e se ofereceram para que analistas e intérpretes pudessem visitar as tensões que, aqui, configuram a dialética entre o particular e o universal.

Se o Brasil participa a seu modo do processo que desde o século XIX vai conferindo uma forma escolar à educação, que com uma materialidade própria produz a escola seriada e progressiva como módulo de expansão do acesso, é justamente no modo como a desigualdade cria marcadores sociais para as diferenças que a escola pública oferece recursos significativos para que intérpretes pensem na distância entre acessibilidade e inclusão.

Se permanecermos na órbita da palavra enigma, que deu título a uma das obras aqui comentadas, podemos pensar que o que há de enigmático na relação entre escola e democracia no Brasil não se desvenda com os números crescentes das expansões, que inclusive ocorreram em contextos ditatoriais.

Diz respeito a pensar em como, sem perder a mesma forma, a escola pública vai sendo considerada de "outro padrão", principalmente em relação ao "padrão de clientela" que adentra seus domínios. Se forma e padrão podem não coincidir, o acesso pode ser dar (tal como se deu) ao mesmo tempo em que o bem dado à partilha "perde valor", "deprecia-se".

Os novos intérpretes teriam na escola pública do século XX mais que um tema, mas uma grande oportunidade para refletir sobre o processo que foi produzindo a escola urbana por dentro dos processos de mobilidade social.

Ou seja, enquanto parte expressiva da sociedade se refere à escola pública com um saudosismo que se reporta a um tempo no qual ela não somente ensinava, mas principalmente participava da demarcação de distâncias entre estratos mais ou menos escolarizados, resta inconclusa a tarefa de pensar historicamente não a escola que tínhamos e perdemos, mas exatamente aquela que produzimos com nosso modo de jogar o jogo de aproximação e distanciamento de todos com todos. 
Inclusão, palavra do final do século XX pode ser projetada sobre o passado sem que isso represente uma deliberada produção de anacronismo. Pode ser aqui apropriada como recurso interpretativo para analisar as particularidades desse roteiro para se compreender o enigmático país que construímos nos trópicos.

A ampliação de vagas foi acompanhada de um crescente processo de desprofissionalização da atividade docente com a contínua e progressiva busca por recursos "modernizadores" que pudessem garantir a apropriação de conteúdos "a despeito" da ação docente, considerada cada vez mais menos preparada.

A ampliação do acesso teria sido efetivamente mais inclusiva se a heterogeneidade que marca a sociedade brasileira fosse reconhecida, tal como pedia Anísio Teixeira, como ponto de partida e não como dado de inviabilidade de seus propósitos?

Há que se desvendar a causa que faz com que intelectuais da educação e suas produções não figurem entre os intérpretes do Brasil, quando intérpretes são elencados. É preciso, pois, perguntar: por que nessas obras a educação pública, sua presença ou ausência, não comparece como um tema importante para se interpretar o país quando seus organizadores(as) e autores(as) são, todos eles(as) ardorosos defensores da escola pública -da educação infantil ao ensino superior- como um direito social fundamental e como uma condição para o estabelecimento da democracia entre nós?

Ao que parece, expulsa dos domínios da história (Cardoso e Vainfas, 1997), a educação estaria também sendo esquecida pelos novos intérpretes do Brasil como uma chave importante para entender o que somos e como nos constituímos. Mas seria isso verdadeiro para todos os brasis? Será que a ausência da referência à escola pública nas interpretações atuais do Brasil nos diz, também, da auto representação de nossa intelectualidade e de sua relação com aqueles "outros" que frequentam a escola pública básica? Não estaria aí, também, uma chave para entender por que é contínua a referência à universidade e ao ensino superior para se entender o Brasil, mas não à escola primária.

No caso do Brasil, chama a atenção que mesmo quando se discute estes temas e, sobretudo, quando se discute sobre as condições para o revigoramento da esfera e da participação públicas, ou, dizendo de outra forma, quando se propõe o fortalecimento da democracia e do jogo democrático entre nós, mesmo assim, muito pouco se discute sobre o papel da escola pública nesta tarefa. Há, por assim, dizer, um esquecimento da escola pública no debate público dos intelectuais brasileiros sobre a democracia, a esfera pública e a participação política. É como se, infelizmente, nossa intelectualidade estivesse acreditando que é possível construir uma sociedade democrática sem o concurso de uma escola pública de qualidade. 
Dentre os indícios desse esquecimento está, em primeiro lugar, o fato de nenhum dos intelectuais convidados para figurar nos livros ou para participar de debates/seminários como aqueles organizados há duas décadas por Adauto Novais ${ }^{3}$, ter uma trajetória de reflexão sistemática sobre a sorte da escola pública, de nível fundamental, no Brasil. Quase todos trabalham em universidades e, talvez por isso, estão muito mais preocupados com as políticas de cotas para acesso à universidade do que com o que se passa na escola pública de ensino fundamental do país. Outro indício do esquecimento é a ausência, nos debates, de uma reflexão fundamentada e sistematizada sobre a importância da escola pública de qualidade para o jogo democrático no país.

Convém ressaltar, no entanto, que nem sempre foi assim. Ou seja, nem sempre os intelectuais brasileiros estiveram tão pouco preocupados com a escola pública que não seja a de nível superior. Desde o século XIX, sobretudo a partir da independência, setores expressivos da intelectualidade brasileira sempre estiveram convencidos da importância da democratização da escola como um índice da democratização da sociedade e como condição do aprendizado de uma cultura política pública.

De Bernardo P. de Vasconcelos, passando por Tavares Bastos, Rui Barbosa, Francisco Campos, Gustavo Capanema, Anísio Teixeira até Florestan Fernandes e Paulo Freire, mesmo com marcadas diferenças políticas, há uma crença unânime na importância da escola pública fundamental para o projeto de país que todos defendiam. Não era, para eles, possível pensar em um projeto Nação sem defender que a escola faria parte, como produto e produtora, de tal projeto.

É possível pensar as reflexões de um Pierre Bourdieu, sem lembrar as suas fundamentais e seminais pesquisas sobre a escola francesa? Do mesmo modo, é possível esquecer as fundamentais lições de Edgard Morin sobre a importância da escola para o futuro da democracia?

Há, pois, que se perguntar sobre o significado do esquecimento da escola pública pelos intelectuais brasileiros. Porque será que já não preocupam tanto com a sorte da escola pública, mesmo quando discutem as condições de possibilidade de fortalecimento da democracia? Será por que, definitivamente no Brasil, a escola pública foi abandonada pela classe média, estrato de onde vem a maioria dos intelectuais? Será por que, uma vez mais, a escola pública é a escola dos outros já que a nossa escola, a dos nossos filhos e filhas, é a escola privada?

O problema é que uma resposta positiva a qualquer uma das questões acima coloca-nos uma séria questão: com quem e para quem queremos construir a democracia neste país? Se abrirmos mão de uma defesa vigorosa

\footnotetext{
${ }^{3}$ Professor e jornalista, dirigiu, durante vinte anos, o Centro de Estudos e Pesquisas da Fundação Nacional de Arte/Ministério da Cultura e é responsável pela organização de Seminários Nacionais que, desde o início da década de 1990, reúne os principais intelectuais brasileiros na discussão dos grandes tema nacionais e internacionais.
}

Araucaria. Revista Iberoamericana de Filosofia, Política y Humanidades, año 19, n 38. Segundo semestre de 2017. Pp. 345-364. ISSN 1575-6823 e-ISSN 2340-2199 doi: 10.12795/araucaria.2017.i38.15 
da escola pública estaremos, na verdade, abrindo mão da própria esfera pública como condição e possibilidade do jogo democrático. Por mais que a escola pública fundamental seja crítica hoje no mundo inteiro como insuficiente para a formação do cidadão apto para participar da vida pública, a democracia jamais será construída sem a mesma, pelo menos as formas atuais que conhecemos de democracia e de escola. Abrir mão do sonho de uma escola pública de qualidade para todos nós, e não apenas para os filhos dos outros, pode ser uma maneira de perpetuar as desigualdades imensas que hoje existem no país no que diz respeito à participação pública.

O silêncio sobre a educação ou o esquecimento da escola pública por parte de nossos mais importantes intelectuais são, assim, os indícios de mais um dos grandes perigos que rondam a nossa já frágil democracia. 


\section{Referências:}

AZEVEDO, F. A cultura brasileira. São Paulo, Companhia Editora Nacional, 1940.

BOTELHO, A. e SCHWARZ, L. Agenda brasileira. São Paulo, Companhia das Letras, 2011.

BOTELHO, A. e SCHWARZ, L. Um enigma chamado Brasil. São Paulo, Companhia das Letras, 2009.

BUFFA, E. Ideologias em conflito: escolar pública x escola privada. São Paulo, Cortez Editora, 1979.

CARDOSO, Ciro Flamarion, VAINFAS, Ronaldo (Org.) Os domínios da história: ensaios de teoria e metodologia. Rio de janeiro: Campus, 1997

FARIA FILHO, Luciano. M.. Os projetos de brasis e a questão da instrução no nascimento do Império. In: Tarcísio Mauro Vago; Marcilaine Soares Inácio; Julina Cesário Hamdan; Hércules P. dos Santos. (Org.). Intelectuais e escola pública no Brasil - séculos XIX e XX..Belo Horizonte: Mazza Edições, 2009, p. 19-46.

FRAGA, P. Tancredo Neves: o príncipe civil. Rio de Janeiro, Editora Objetivo, 2017.

FREITAS, M.C. e BICCAS, M.S. História social da educação no Brasil. São Paulo, Cortez Editora, 2009.

FUNDAÇÂO PERSEU ABRAMO. "Percepções e valores políticos nas periferias de São Paulo.” São Paulo, Editora Perseu Abramo, 2017.

MOTA, C. G. e LOPEZ, A. História do Brasil: uma interpretação. São Paulo, Editora 34, 2015.

OLIVEIRA VIANNA, F.J. Instituições politicas brasileiras. Brasília, Biblioteca do Senado 2000 [1949].

SADER, E. PAOLI, M.C. "Sobre classes populares no pensamento sociológico brasileiro." In: CARDOSO, R. (org.) A aventura antropológica. São Paulo, Editora Paz e Terra, 1986, p. 39-68.

SOUZA, Jessé. A tolice da inteligência brasileira: ou como o país se deixa manipular pela elite. São Paulo: LeYa, 2015.

SCHWARZ, L. e STARLING, H. Brasil, uma biografia. São Paulo, Companhia das Letras, 2015.

TEIXEIRA, A. Educação no Brasil. São Paulo, Companhia Editora Nacional, 1962.

WEINSTEIN, B. A (re)formação da classe trabalhadora. São Paulo, Cortez Editora, 2000.

WILLIAMS, R. Keywords. New York, Columbia University Press, 2010. 